\title{
Probation and Parole Officers' Compliance with Case Management Tools: Professional Discretion and Override
}

\author{
Lacey Schaefer \\ School of Criminology \& Criminal Justice; Griffith Criminology Institute, Griffith University \\ $\&$ \\ Harley Williamson
}

School of Criminology \& Criminal Justice; Griffith Criminology Institute, Griffith University

\section{Corresponding Author:}

Lacey Schaefer, $\mathrm{PhD}$

Lecturer

School of Criminology and Criminal Justice; Griffith Criminology Institute Griffith University

Social Sciences Building (M.10)

176 Messines Ridge Road

Mount Gravatt

Australia 4122

Phone: +61 0737353482

Email: 1.schaefer@griffith.edu.au

\section{Other Authors:}

Harley Williamson

$\mathrm{PhD}$ Candidate

School of Criminology and Criminal Justice; Griffith Criminology Institute

Griffith University

Social Sciences Building (M.10)

176 Messines Ridge Road

Mount Gravatt

Australia 4122

Phone: +61458427539

Email: harley.williamson@griffithuni.edu.au

Version accepted for publication at the International Journal of Offender Therapy and Comparative Criminology. 
Compliance with Case Management Tools 


\begin{abstract}
Actuarial assessment has become an integral component of offender management, helping to structure the decision-making of correctional staff about offenders' case plans. Despite research validating instruments and documenting best practices in offender assessment, fewer studies explore how practitioners use these diagnostic and case management tools. Using survey data from a sample of probation and parole staff, the current study examines the influence of professional characteristics, job burnout and stress, and supervision strategy preferences on noncompliance with assessment data entry and deviations from the tools' risk and needs recommendations. Results indicate various forms of noncompliance with case management tools are fairly common. Staff with greater tenure and heightened depersonalization and emotional exhaustion exhibit greater odds of assessment noncompliance. Case managers who adopt surveillance and rehabilitation supervisory tactics are less likely to deviate from the tools' processes and results, while staff who prefer opportunity-reduction strategies have increased odds of assessment noncompliance.
\end{abstract}




\section{Probation and Parole Officers' Compliance with Case Management Assessment Tools}

Probation and parole work is traditionally shaped around regulating offenders' activities and offering corrective interventions to assist them to live more prosocially and desist from crime (Skeem \& Manchak, 2008). Contemporarily, this goal is often guided by the principles of effective correctional intervention, which stipulate that (1) supervision and intervention intensity should be commensurate with the level of risk of reoffending each offender exhibits (the risk principle), (2) these strategies should target for change those factors that are associated with offending (referred to as criminogenic needs; the needs principle), and (3) these strategies should be responsive to the unique attributes of the individual offender (the responsivity principle). Central to each of these principles is the requirement for a valid assessment of each offender's risk, needs, and responsivity considerations (Andrews \& Bonta, 2010; Andrews, Bonta, \& Wormith, 2006). Further, these assessment tools facilitate consistency and transparency in offender case management to produce actuarial rather than clinical judgments (Oleson, VanBenschoten, Robinson, Lowenkamp, \& Holsinger, 2012).

Yet despite their importance, research highlights that practitioners do not systematically use these tools, which can create disparate and often undesirable offender outcomes (Miller \& Maloney, 2013). While there is a large body of evidence that supports the utility of validated assessments in case managing offenders (Andrews \& Bonta, 2010), recent studies demonstrate that assessment tools are frequently neglected or misused (Miller \& Maloney, 2013; Viglione, Rudes, \& Taxman, 2015). This matter has perhaps become increasingly important as many corrections agencies have struggled to keep pace with rising caseloads and diminishing resources; while some may argue that these tools improve agency efficiencies, it may also be that officers fail to complete assessments as designed due to these workload demands. As an illustration, in an American Probation and Parole Association 
study of the effect of these consequences of workload, one participant stated that, "we believe in the evidence based practices approach, but carrying them out can be difficult" (DeMichele, 2007, p 48). A wealth of research highlights that valid offender assessments are integral to core correctional practices, but the ways in which other relevant principles (such as professional discretion/override and integrity; Andrews \& Bonta, 2010) influence the use of these tools is less understood. This study, therefore, seeks to examine whether probation and parole officers use offender assessments as prescribed. Specifically, we examine how compliant or manipulative staff are with data entry, and the ways that they act outside recommendations made by risk/needs assessments.

\section{The Evolving Role of Probation and Parole Officers}

The seminal work of Klockars (1973) on the typology of probation work identified two poles of rationale exhibited by officers in their understanding of their roles: law enforcers and therapeutic agents. Klockars further identified that along this continuum of practices between enforcement and treatment are two additional orientations: time servers (those who are administratively compliant but otherwise uninvested) and synthetic officers (those who aim to embed enforcement and treatment into supervision). This important study has continued to impact our understanding of probation and parole work, with much research indicating that the two polar strategies identified by Klockars are still influential (Skeem \& Manchak, 2008). Contemporarily, discussions around orientations to probation and parole supervision remain much aligned to the original categories distinguished by Klockars (1973), with two prevailing approaches to community corrections practices: the social work approach, premised on treating and rehabilitating offenders, and the law enforcement approach, focused on the surveillance and social control of offenders. Although much probation and parole work often incorporates some elements of both guiding philosophies under a hybrid model (Taxman, 2008), it is not uncommon for agencies and officers to exhibit a preference for one 
over the other. However, the fusion of both supervision strategies arguably conflict due to their competing objectives and ambiguous roles and responsibilities for officers (West \& Seiter, 2004).

Still, the function of community corrections officers tends to shift between rehabilitation and compliance foci. Following a generation of failed tough-on-crime initiatives, treatment-orientated methods are increasingly used to alter offender behavior and reduce recidivism (Cullen \& Jonson, 2012), witch research identifying cognitive-behavioral interventions as the gold standard in offender rehabilitation (Lowenkamp, Latessa, \& Holsinger, 2005). These treatment efforts require individualized case management that addresses offenders' unique criminogenic risks and needs (Andrews \& Dowden, 2007). While these strategies can be effective (Andrews \& Bonta, 2010), they require an active and engaged approach to community correctional supervision. Caseload sizes often result in passive and generic probation and parole practices emphasizing service brokerage (Miller, 2015; Solomon et al., 2008; Turner, 2010). Thus, the daily pressures on correctional officers to supervise a high volume of offenders impacts their ability to individualize their approach. While several case management tools encourage officer consistency (and adherence to best practices), little is understood about officers' commitment to these tools (Luong \& Wormith, 2011; Miller \& Maloney, 2013).

\section{Risk and Needs Assessments in Probation and Parole}

Risk/needs assessment tools are crucial to improving corrections practices. They enable resources to be appropriately allocated to improve offender outcomes through implementing treatment programmes and control strategies specific to each offender (Viglione et al., 2015). As officers often prioritise or embody an enforcement- or treatmentfocused approach in their case management of offenders, these tools help produce more consistent outcomes within and between caseloads (Andrews \& Dowden, 2006; Andrews et 
al., 2006). These tools also arguably improve the efficacy of officer actions, as they provide decision-making criteria and standardized methods and results as opposed to subjective judgments made by corrections officers (Oleson et al., 2012).

The use of prediction-based tools stems back to the 1800s (Gottfredson \& Tonry, 1987). Early iterations of these tools by scholars such as Burgess (1968) and Glueck and Glueck (1950) highlight the applicability of actuarial assessment tools to predict elements of criminogenic risk. Later refinement of these tools enables practitioners to predict different elements of risk, such as recidivism, re-arrest or breaching bail conditions (Gottfredson \& Moriarty, 2006). They subsequently provide a more effective measurement of risk than human evaluations (Andrews et al., 2006). Risk assessment tools now include aspects related to static and dynamic needs, such as substance use, peer influences and pro-social activities (e.g., employment; Andrews \& Dowden, 2006). As such, criminogenic and non-criminogenic needs can be targeted through supervision and intervention (Miller \& Maloney, 2013).

While not without criticism, the Risk-Need-Responsivity (RNR) model is arguably the most influential framework for identifying criminogenic risks and needs, and developing responses that consider the offender's motivation, cognitive ability, and learning style to maximise their responsivity (Andrews, Bonta \& Wormith, 2011). These RNR principles guide popular case management tools, such as the Level of Service Inventory-Revised (LSI-R; Andrews \& Bonta, 1995) and the Level of Service/Case Management Inventory (LS/CMI; Andrews et al., 2006). These tools are premised on developing the most appropriate case management approach to address criminogenic needs in ways that are commensurate to risk and responsive to the individual traits of the offender. In recent years, a fourth element of RNR has been introduced: "professional override” (Andrews \& Bonta, 2010, p. 52). Professional override stipulates that once considering the individual's risk, needs and 
responsivity, the officer must make the final decision on the most appropriate outcome for the offender.

Compliance and Noncompliance with Case Management Tools

Probation and parole officers do not always comply with assessment tools, due primarily to two factors. Firstly, noncompliance may occur by completing assessment tools favouring a particular outcome (Gebo, Stracuzzi, \& Hurst, 2006). Secondly, officers sometimes disregard assessment results and rely on human judgment and professional override when making case management decisions (Shook \& Sarri, 2007). While it may seem that officers would thus have a preference for clinical judgment over actuarial decisions, it may be due to external factors (such as resource restrictions) hindering officers' capacity to apply recommendations from the tools (Gebo et al., 2006). This suggests that there may be important differences in the factors that motivate (non)compliance with these instruments.

Historically, research about compliance in probation and parole has largely centered around offenders' adherence to conditions on their orders. Within this vein, Bottoms (2001) identified differences between instrumental compliance and normative compliance, while Robinson and McNeill (2008) distinguish between formal compliance and substantive compliance. These variations in forms of compliance highlight whether individuals adhere to rules based on a rational choice or as a more value-laden engagement. Although research on probation and parole officers' compliance with case management tools has been slower to come, it is possible that the reasons underpinning (non)compliance with assessments are comparable to the factors seen in the above typologies of offender compliance (and more broadly, in categorizations of community corrections officers' orientations to their work; Klockars, 1973; Mawby \& Worrall, 2011).

Toward this end, in a recent study of compliance amongst corrections staff, Miller and Maloney (2013) found that noncompliance manifests in various ways, including failing to 
complete assessment tools, manipulating responses to elicit certain results, and neglecting to use findings from assessment tools during the decision-making process. The authors identified three sub-sets of corrections officers: substantive compliers (those who complete tools carefully and honestly), bureaucratic compliers (tool completion as required but likely to disregard the results), and cynical compliers (more conscious subversion of the tool, such as manipulative completion or a disregard of the results). The authors concluded that noncompliance largely resulted from negative perceptions towards assessment tools and deficiencies in training (Miller \& Maloney, 2013). In a similar study, Luong and Wormith (2011) concluded that noncompliance with risk measurement tools was due to pessimism amongst practitioners in believing these tools reduced recidivism. Despite these findings, positive perceptions and increased skills around risk assessment principles have been associated with improved offender outcomes (Vincent, Guy, Gershenson, \& McCabe, 2012).

Yet despite the large evidence-base surrounding the theory and use of the RNR model, these principles are not without criticism (Fazel, Singh, Doll, \& Grann, 2012; Haines \& Case, 2008; Hannah-Moffat, 2005; Kemshall, 2003; Miller, 2014; Robinson, 2015). Perhaps foremost is the concern that, as criminal justice system interventions have emphasised managerialism, the 'justice' component has been trumped by the 'system' component. Toward this end, some scholars have speculated that the RNR model has subtly transformed into a risk-obsessive platform or has been co-opted for more punitive ends (Kemshall, 2003; Miller, 2014; Robinson, 2015). More practically, a growing body of research has called attention to the somewhat limited predictive power of popular risk and needs assessments (Fazel et al., 2012; Yang, Wong, \& Coid, 2010). There are also philosophical, epistemological, and methodological concerns regarding the prediction of future behavior for current punishment purposes, and it may be that assessment noncompliance stems from these concerns. Related to these matters, corrections practitioners may circumvent assessment 
processes or fail to adhere to assessment recommendations when they conflict with their own occupational values (Cheliotis, 2006; Grant, 2016; Mawby \& Worrall, 2013).

Reflecting on these potential shortcomings, it is clear that the merits of the RNR model are not uncontested, and the principles are likely to transform in the future (Ziv, 2017). Still, at present, assessment tools are firmly embedded in case management practices. These considerations combined, it is increasingly important to understand how practitioners perceive and utilise these tools. Their practical application is complex due to resource constraints and the need to integrate dynamic human factors amongst each offender (Taxman \& Pattavina, 2013). Moreover, tools combining risks and needs assessments often neglect offender needs, can inappropriately heighten an offender's risk (Austin, 2006), and may negatively impact treatment programming (Viglione et al., 2015). Assessment results often do not manifest into individualized case plans targeting factors pertinent to each offender (Taxman, Yancy, \& Bilanin, 2006). Understanding why case management tools are used inconsistently in probation and parole is this study's focus.

\section{Method}

Although best practice in evidence-based corrections largely advocate using fourth generation case management tools, recent studies suggest probation and parole officers do not complete these instruments as instructed and incorporate results inconsistently (Miller \& Maloney, 2013; Viglione et al., 2015). Accordingly, this project asks: 1) What is the degree of assessment noncompliance among probation and parole officers? 2) What are the variable manifestations of this noncompliance? 3) What factors are associated with this noncompliance? We answer these questions using self-report survey data (collected in 2016) from community corrections staff in a large metropolitan area in Australia (a jurisdiction that utilizes probation and parole practices comparable to those used in other first world nations). Staff in this metropolitan region were selected as the sample because (compared to staff 
working in more unique areas of the geographically vast state) we hypothesised that their experiences would be more representative of traditional probation and parole work. The survey was available online and all probation and parole staff in the region were provided with an email invitation to participate. Of the 125 staff working as probation and parole officers in the area (all of whom assess and supervise offenders), 75 individuals completed the online survey $(60 \%$ response rate).

The study was approved by the human research ethics committees of both the university and corrections agency. Participation was voluntary and no incentive was provided. Participants were first given information about the study and ticked several boxes to communicate that they understood the study goals, procedures, risks, and benefits; only after this informed consent process was completed did the survey become available. Upon providing informed consent, respondents were asked about their use of case management tools, supervision strategies, role orientations, job satisfaction and stress, attitudes toward offenders, and reporter characteristics. Descriptions of the measures used for our analyses are included below. Two reminder emails were sent to increase the response rate (at two and four weeks after the initial invitation). Survey completion times averaged 20 minutes.

\section{Use of Case Management Tools}

We included three sets of analyses in this paper, each containing four dependent variables. The measures used are drawn from Miller and Maloney's (2013) study. Respondents were asked how frequently they engage in behaviors related to using case management tools. Available responses ranged on a seven-point Likert scale from never to always. Given the skewed distribution of each variable, we categorised the measures into respondents who reported "always" and "nearly always" or "never" and "nearly never" performing the act in question, versus those who varied in their work performance (i.e., those who "sometimes" deviate from the requirements of the case management tool). 
In the first analyses, we conducted a multivariate logistic regression predicting compliance with data entry. The second analyses predicted compliance with risk recommendations. The third analyses predicted compliance with needs recommendations. The measures used for each scale and percentages of participant responses to these dependent variables are shown in Figure 1.

\section{Professional Characteristics}

We speculated three professional characteristics would influence officer compliance with case management tools. First, we included a categorical variable reflecting the staff member's position (case manager $=28 \%$; senior case manager $=43 \%$; other position (e.g., program delivery, services officer, or supervisor) $=29 \%$ ). Next, length of employment measured how many months the individual has worked in probation and parole case management $(R=0-204, M=66.83, S D=58.59)$. Finally, we included a perceptions of assessment validity scale, which includes ten Likert-scale items measuring respondents' agreement $(0=$ strongly disagree; $6=$ strongly agree $)$. Statements included "I am confident in the validity of the assessment tools we use". The final scale is an average of participants' responses to these ten items $(\alpha=.879, R=.75-5.13, M=3.95, S D=1.03)$.

\section{Job Burnout and Stress}

We hypothesized the amount of professional strain or satisfaction each officer experiences in their work may impact compliance with assessment processes and results. Thus, we included three measures of job burnout and stress drawn from the Maslach Burnout Inventory (Maslach \& Jackson, 1981). The inventory includes 22 items asking respondents to indicate how often they experience a particular feeling because of their current job (ranging from $0=$ never to $6=$ everyday). The items are organized around three different dimensions aggregated into a mean scale for our analyses. The depersonalization scale includes five items $(\alpha=.705, R=0-3.60, M=1.20, S D=.87)$ with statements such as "I feel 
I treat some offenders as if they were impersonal objects." The emotional exhaustion scale includes nine items $(\alpha=.881, R=.11-5.00, M=2.01, S D=1.06)$ with prompts including "Working with offenders all day is a real strain for me." Higher scores on both scales represent greater job burnout and stress. The personal accomplishment scale includes eight items $(\alpha=.738, R=2.25-5.75, M=4.33, S D=.86)$ with statements such as "I have accomplished many worthwhile things in this job." Higher scores on the scale reflect less professional burnout and stress.

\section{Supervision Strategies}

We hypothesized that the staff member's preferred supervision strategies may also influence the use of case management tools, whereby they may manipulate data entry or prioritize/neglect certain results to accommodate their supervision style. Our analyses include three independent variables measuring three supervision strategies probation and parole officers often use: surveillance, rehabilitation, and opportunity-reduction (drawn from Miller, 2012). Respondents were asked to indicate how frequently they rely on particular strategies (from $0=$ never to $6=$ always). The surveillance strategies scale includes five items as a mean scale $(\alpha=.868, R=2.40-6.00, M=4.35, S D=.83)$ with tactics such as "remind probationer/parolee of legal consequences of behaviours." The rehabilitation strategies scale comprised five items as a mean scale $(\alpha=.898, R=3.40-6.00, M=4.84, S D$ $=.63)$ with strategies such as "connect probationers/parolees with appropriate therapeutic services." The opportunity-reduction strategies scale includes eight items included in a mean scale $(\alpha=.874, R=1.13-5.75, M=3.55, S D=1.19)$ with prompts such as "help probationers/parolees recognize and avoid places where they are at risk of offending." Higher scores on each scale represent a greater use of that strategy.

\section{Results}


Foremost, the results of this study show overall, there is less compliance with data entry processes among staff compared to similar studies (e.g., Luong \& Wormith, 2011; Miller \& Maloney, 2013). As seen in Figure 1, noncompliance is somewhat common and manifests itself in a variety of ways. When asked how often each staff member completed the case management tool as required, $37 \%$ of respondents indicated that it was less than $70 \%$ of the time (a further $10 \%$ of the sample indicated that it was less than $40 \%$ of the time). Approximately one-third of participants reported they sometimes complete the tool carelessly, with another quarter indicating they minimize, exaggerate, or manipulate information entered in the tool. Also, large proportions of community corrections staff surveyed at least sometimes deviated from the risk/needs recommendations provided by the tool. More than half the sample reported they sometimes make more- or less-restrictive risk-based decisions than what the tool indicated. Probation and parole staff frequently targeted needs not identified in the assessments (78\%), while $44 \%$ of respondents indicated they sometimes disregard some criminogenic needs highlighted by the tool.

Following from these descriptive findings, we performed three logistic regressions: four dependent variables predicted compliance with data entry, four outcomes predicted compliance with assessment risk recommendations, and four predicted compliance with assessment needs recommendations. For ease of interpretation, we report the odds ratios $\left(e^{\wedge b}\right)$ of moving from 0 ("always" or "never") to 1 ("sometimes") on the dependent variable. In this way, we showcase the factors influencing staff members' variation in performance from what is prescribed. Rather than describe the results in full (located in the following tables), this section aims to highlight the general themes emerging from our analyses.

In our first group of models, we performed four logistic regressions (see Table 1). Each dependent variable measured an aspect of self-reported compliance with data entry processes related to assessment completion: filling out the tool carefully (Model 1), 
exaggerating information (Model 2), minimizing information (Model 3), and manipulating information (Model 4). In predicting staff members' data entry completion, the odds of case managers sometimes failing to address every question in the assessment is five times greater than for staff members in other positions $(O R=4.977, p<.01)$. Staff who indicated that they adopt a surveillance style of supervision were at reduced odds of skipping questions on the tool $(O R=.543, p<.05)$. Longer lengths of employment, greater depersonalization, and increased emotional exhaustion increased the odds of staff members exaggerating, minimizing, or manipulating data entered in the tool, while adopting surveillance and rehabilitation supervision strategies decreased the odds of data mismanagement. One interesting variation is that the odds of exaggerating $(O R=.419, p<.01)$ and minimizing $(O R$ $=.480, p<.05)$ certain characteristics is approximately halved with increases in personal accomplishment, while the odds of manipulating data $(\mathrm{OR}=1.919, p<.05)$ are nearly doubled.

In our second group of models, we included four logistic regressions predicting compliance with risk recommendations made by the tool (see Table 2). The dependent variables include decision-making that corresponds exactly with the tool (Model 5), making more restrictive decisions (Model 6), making less restrictive decisions (Model 7), and making decisions without consulting the tool (Model 8). Staff who report greater degrees of emotional exhaustion from their work are at 2.5 times greater odds to fail to comply with the risk recommendations of the tool $(O R=2.678, p<.001)$, with enhanced odds for staff who rely on rehabilitation and opportunity supervision strategies. For staff who report using surveillance tactics with their supervisees, the odds of making decisions not reflecting the tool's recommendations are halved $(O R=.492, p<.05)$. However, adopting these surveillance strategies produces greater odds of more restrictive decision making surrounding risk $(O R=2.744, p<.001)$. Senior case managers were at 3.5 times greater odds of making 
less restrictive decisions about risk than staff in other positions $(O R=3.493, p<.01)$. Interestingly, greater beliefs in the assessment tools' validity is associated with greater odds of making less restrictive decisions regarding offender risk $(O R=1.941, p<.01)$.

In our third group of models, we estimate the odds of staff members' compliance with the needs recommendations of the case management assessments (see Table 3). The outcome variables include staff targeting the needs highlighted (Model 9), disregarding some needs recommendations (Model 10), targeting needs not highlighted (Model 11), and making decisions about offenders' criminogenic needs without consulting the tool (Model 12). The odds of staff members exactly targeting offenders' needs resulting from the assessment are higher among senior case managers $(O R=2.780, p<.05)$, those with greater tenure $(O R=$ $1.009, p<.05)$, those with greater degrees of depersonalization $(O R=2.038, p<.05)$, and for staff who rely on opportunity-focused supervision strategies $(O R=5.411, p<.001)$. The odds of deviating from the needs recommendations of the tool are approximately halved with increased perceptions of the validity of the assessment $(O R=.565, p<.05)$ and greater feelings of personal accomplishment $(O R=.539, p<.05)$. However, enhanced sensations of personal accomplishment in work also lead to greater odds of the staff member making decisions about offender needs without consulting the tool $(O R=1.947, p<.01)$. The adoption of surveillance and rehabilitation strategies are associated with decreased odds of deviating from the needs recommendations of the tools, while the use of opportunityreduction tactics enhances the odds of noncompliance.

Across all models, several clear themes emerge. First, senior case managers and staff with longer employment history in corrections exhibited greater odds of noncompliance with the case management tools. This may indicate that greater familiarity with the assessments enhances confidence or self-efficacy, thereby leading to deviations from the processes prescribed by the agency and the outcomes recommended by the tools. Second, greater 
feelings of depersonalization and emotional exhaustion also increased the odds of noncompliance across many outcomes. Third, surveillance and rehabilitation supervision strategies are largely associated with decreased odds of noncompliance, while adopting opportunity-reduction tactics increases the odds for deviations in risks and needs recommendations of the assessment tools.

However, two independent variables exerted different directions of effect on compliance outcomes. First, the perceptions of assessment validity scale was a significant predictor in two models, working in opposite ways. Increased belief in the validity of case management tools was associated with greater odds of making less restrictive decisions about offenders' risk levels, but with diminished odds of targeting criminogenic needs not highlighted by the tool. In other words, staff members who believe the tools are valid are at increased odds of minimizing offenders' risk, but have lower odds of adhering to the criminogenic needs the tool recommends. Second, the role of personal accomplishment was also mixed. Greater sense of accomplishment was associated with greater odds of making less restrictive decisions about risk and making decisions about criminogenic needs without consulting the tool. However, greater personal accomplishment was also associated with increased odds of data entry compliance and conforming to the needs highlighted by the tool. Thus, personal accomplishment leads to targeting criminogenic needs identified in assessments but also making recommendations without consulting the assessment's results. This may indicate that more (self-identified) accomplished staff are compliant with the needs recommendations for offenders, but have become proficient in predicting those domains of criminogenic needs without looking at the results. The level of personal accomplishment among staff was not associated with employment length $(r=-.028, p=.858)$, although senior case managers exhibited slightly higher rates of accomplishment than staff in other positions $(F=3.086, p<.05)$. 


\section{Discussion}

Empirically validated actuarial assessments are integral to measure risks and criminogenic needs of offenders under community supervision. In addition to diagnostic utility, contemporary assessments also guide case management processes, providing triaged and individualized recommendations for offenders to help structure probation and parole officers' decisions. Yet while there are a host of best practices in offender risk/needs assessment, little research has explored users' adherence to the processes and outcomes of these tools. Some studies demonstrate correctional staff may question assessment validity (Austin, 2006; National Institute of Corrections, 2003), and are often noncompliant with the assessments they perform. Some officers manipulate data entry or make decisions that do not correspond with assessment recommendations (Bonta, Rugge, Scott, Bourgon, \& Yessine, 2008; Krysik \& LeCroy, 2002; Miller \& Maloney, 2013). Beyond measuring the validity of case management assessment tools, research must explore how community corrections agents use them (Harris, 2006).

Our study sought to remedy this gap, using survey data from a sample of probation and parole staff to predict compliance with offender assessments. We extend similar projects by outlining the results separately for data entry processes and staff decision making related to offender risk and criminogenic needs. We further include models analyzing the nature of noncompliance (e.g., separately predicting both the decision to make a more and less restrictive risk-based decision). The current study also furthers the knowledgebase about practitioner adherence to risk/needs assessments by including elements of job stress and the officers' preferred supervision strategies as predictors.

Our analyses demonstrate that noncompliance with the tools across case management decisions is more common among senior case managers and those who have been employed with the department for longer periods. This finding may result from personal beliefs about 
the superiority of clinical judgment or due to increased confidence among these staff. Indeed, some studies demonstrate that corrections practitioners operate with considerable agency, such that their professional performance is reflective of their individual occupational values (Cheliotis, 2006; Grant, 2016; Mawby \& Worrall, 2011, 2013). This may help to explain why some probation and parole officers fail to comply with offender assessment processes and recommendations, as the organization's ideologies and subsequent practices may conflict with the staff member's professional identity (e.g., a tool may recommend more stringent supervision conditions or heightened monitoring, which may be circumvented if the officer embodies a treatment orientation in his or her supervision practices).

We also speculate noncompliance may result from the resource constraints present in probation and parole work (and indeed, the area in which this study was conducted has exceptionally high caseloads). For instance, some research showcases that correctional staff may deviate from tool treatment recommendations due to resource unavailability (Shook \& Sarri, 2007). Community and treatment services in the study location are limited, and correctional agencies frequently complain about the lack of supply to meet the demand. Thus, rather than staff members manipulating data entry or ignoring case plan recommendations for nefarious reasons, it is possible they are completing assessments and making decisions within the bounds of practical resource concerns. Future research must unpack why community corrections officers fail to complete assessments, misrepresent offender data upon input, and sidestep case plan recommendations made from these tools.

The probation and parole staff in our survey reported that they dedicate a large proportion of worktime to administrative tasks, such as assessments and report-writing (on average, $38 \%$ of the working week). We thus speculated that the individual's orientation to their work may influence the way they approach these bureaucratic requirements. First, we included three measures of job burnout and stress, finding that greater depersonalization and 
emotional exhaustion led to increased odds of noncompliance with case management assessment tools. However, the third subscale of personal accomplishment had mixed results. Staff who reported a sense of accomplishment resulting from their work were at decreased odds of exaggerating and minimizing data, but had nearly twice the odds of manipulating information to obtain results. This result may be semantic confusion among respondents, or may indicate that staff members 'manipulate' information in ways other than simply over- or under-stating what the offender reports (e.g., perhaps staff add data the tool does not call for, or incorporate information from sources other than the offender). Personal accomplishment was also associated with less restrictive risk-based decisions as well as making needs-based decisions without consulting the tool's results. Compared to the results for tenure (position and length of employment), we speculate increased confidence about work abilities lead to greater assessment noncompliance.

Second, we hypothesized that staff members' preference for certain supervision strategies may influence how they approach assessments. We included three scales measuring different supervisory tactics, generally finding case managers who rely on surveillance and rehabilitation approaches to offender supervision are at decreased odds of deviating from the tools, while officers who use opportunity-focused strategies have greater odds of noncompliance (for $7 / 8$ of the risks and needs outcomes). This may be because opportunity-reduction approaches to offender supervision are relatively new (previous work by the authors, 2016), and assessment instruments do not yet contain measures reflecting offenders' opportunity-related risks. Consequently, case managers may make decisions about offenders' risk and criminogenic needs with considerations beyond the scope of traditional assessments (such as information about the offender's social networks, time usage, or offending hotspots). We believe that these are important findings, highlighting how 
probation and parole staff may be using assessments differentially depending on their work stress and habits.

Despite these contributions, the current study is not without limitations. First, the sample size was small, which restricted our ability to perform some auxiliary analyses, and which impacts the generalizability of our results. Our study may also be skewed by metropolitan or Australian sampling, and will require replication in rural contexts and other nations (despite this study's sample comparability to other Anglophone community corrections agencies). Additionally, although the survey response rate is respectable, we suspect participants may differ from non-respondents, as the staff self-selected to complete the questionnaire. Finally, it is possible that self-reported responses from probation and parole staff may not be accurate due to recall errors, perceptions of their performance, or concerns about the anonymity of their answers. Although several measures were taken to encourage participation and enhance honesty, it is understandable that staff may have been apprehensive about fully disclosing the ways in which they are noncompliant with case management tools (a core aspect of their role). To combat these limitations, further research is needed. Future studies should explore the frequency and nature of assessment noncompliance, building the knowledgebase about what predicts deviation and how to better understand the case management decisions of correctional staff.

Notwithstanding these shortcomings, our study provides important contributions to the literature. Our results highlight the importance for scholars and practitioners to recognize the various reasons why correctional staff fail to adhere to data entry requirements and deviate from the risk/needs recommendations of assessment tools. Although there are some consistent trends, the job stress and supervision strategies differentially impact the types of noncompliance observed. This conclusion has four implications. First, researchers must continue to investigate how practitioners use assessments, moving beyond evaluations of 
instrument validity. There may be pragmatic grounds for why staff deviate from these tools (such as resource deficiencies). Second, given the enhanced odds of assessment noncompliance for more tenured staff and those experiencing depersonalization and emotional exhaustion resulting from their work, correctional agencies must develop techniques to combat work stress or deter its impact on noncompliance with case management tools. Third, given the strong associations between officers' preferred supervision strategies and the odds of assessment (non)compliance, researchers should further explore the role of job orientation on tool use. Community corrections organizations should aim to develop further consistency between the tactics used by staff. Fourth, there is a large literature about how the proper use of validated assessments predict case management practices and offender outcomes. Yet, virtually no information exists about how certain types of assessment noncompliance produce differential impacts on offenders. It is unclear whether officers' professional override of tool recommendations has real implications for how offenders are supervised and how they subsequently fare. Collectively, the findings of this study showcase that probation and parole staff are not always using assessment processes and outcomes as required, and highlight the need to further understand why this may be. 


\section{References}

Andrews, D. A., \& Bonta, J. (2010). The psychology of criminal conduct ( $5^{\text {th }}$ ed.). New Providence, NJ: LexisNexis.

Andrews, D. A., \& Bonta, J. (1995). The level of supervision inventory-revised. Toronto: Multi-Health Systems.

Andrews, D. A., Bonta, J., \& Wormith, J. S. (2011). The risk-need-responsivity (RNR) model: Does Adding the Good Lives Model Contribute to Effective Crime Prevention?. Criminal Justice and Behavior, 38(7), 735-755.

Andrews, D. A., Bonta, J., \& Wormith, J. S. (2006). The recent past and near future of risk and/or need assessment. Crime and delinquency, 52(1), 7-27.

Andrews, D. A., \& Dowden, C. (2007). The risk-need-responsivity model of assessment and human service in prevention and corrections: Crime-prevention jurisprudence. Canadian Journal of Criminology and Criminal Justice, 49(4), 439-464.

Andrews, D. A., \& Dowden, C. (2006). Risk principle of case classification in correctional treatment a meta-analytic investigation. International journal of offender therapy and comparative criminology, 50(1), 88-100.

Austin, J. (2006). How much risk can we take-The misuse of risk assessment in corrections. Federal Probation, 70(2), 58-63.

Bonta, J., Rugge, T., Scott, T., Bourgon, G., \& Yessine, A. (2008). Exploring the black box of community supervision. Journal of Offender Rehabilitation, 47(3), 248-270.

Bottoms, A. E. (2001). Compliance and community penalties. In A. Bottoms, L. Gelsthorpe, \& S. Rex (Eds.), Community penalties: Changes and challenges (pp. 87-116). Portland: Willan.

Burgess, E. W. (1968). Factors determining success or failure on parole. In A. A. Bruce, A. J. Harno, E. W. Burgess, \& J. Landesco (Eds.). The workings of the indeterminate- 
sentence law and the parole system in Illinois (pp. 205-234). Montclair, NJ: Patterson Smith.

Cheliotis, L. K. (2006). How iron is the iron cage of new penology? The role of human agency in the implementation of criminal justice policy. Punishment \& Society, 8, 313340.

Cullen, F. T., \& Jonson, C. L. (2012). Correctional theory: Context and consequences. Thousand Oaks, CA: Sage.

DeMichele, M. T. (2007). Probation and parole's growing caseloads and workload allocation: Strategies for managerial decision making. Lexington, KY: American Probation and Parole Association.

Fazel, S., Singh, J. P., Doll, H., \& Grann, M. (2012). Use of risk assessment instruments to predict violence and antisocial behaviour in 73 samples involving 24,827 people: Systematic review and meta-analysis. BMJ, 345, e4692.

Gebo, E., Stracuzzi, N. F., \& Hurst, V. (2006). Juvenile justice reform and the courtroom workgroup: Issues of perception and workload. Journal of Criminal Justice, 34(4), 425-433.

Gottfredson, D. M., \& Tonry, M. (Eds.). (1987). Prediction and classification: Criminal justice decision making. Chicago: University of Chicago Press.

Gottfredson, S. D., \& Moriarty, L. J. (2006). Statistical risk assessment: Old problems and new applications. Crime \& Delinquency, 52(1), 178-200.

Glueck, S., \& Glueck, E. (1950). Unraveling juvenile delinquency. Juvenile Court Judges Journal, 2, 32 .

Grant, S. (2016). Constructing the durable penal agent: Tracing the development of habitus within English probation officers and Scottish criminal justice social workers. British Journal of Criminology, 56, 750-768. 
Haines, K., \& Case, S. (2008). The rhetoric and reality of the 'risk factor prevention paradigm' approach to preventing and reducing youth offending. Youth Justice, 8, 5-20.

Hannah-Moffat, K. (2005). Criminogenic needs and the transformative risk subject: Hybridizations of risk/need in penality. Punishment \& Society, 7, 29-51.

Harris, P. M. (2006). What community supervision officers need to know about actuarial risk assessment and clinical judgment. Federal Probation, 70(2), 8-14.

Kemshall, H. (2003). Understanding risk in criminal justice. Philadelphia: Open University Press.

Klockars, C. B., Jr. (1973). A theory of probation supervision. Journal of Criminal Law and Criminology, 63, 550-556.

Krysik, J., \& LeCroy, C. W. (2002). The empirical validation of an instrument to predict risk of recidivism among juvenile offenders. Research on Social Work Practice, 12(1), 7181.

Lowenkamp, C. T., Latessa, E. J., \& Holsinger, A. M. (2006). The risk principle in action: What have we learned from 13,676 offenders and 97 correctional programs?. Crime \& Delinquency, 52(1), 77-93.

Luong, D., \& Wormith, J. S. (2011). Applying risk/need assessment to probation and its impact on the recidivism of young offenders. Criminal Justice \& Behavior, 38(12), 1177-1199.

Maslach, C., \& Jackson, S. E. (1981). The measurement of experienced burnout. Journal of Organizational Behavior, 2(2), 99-113.

Mawby, R. C., \& Worrall, A. (2011). Probation workers and their occupational cultures. Leicester, UK: University of Leicester.

Mawby, R. C., \& Worrall, A. (2013). Doing probation work: Identity in a criminal justice occupation. London: Routledge. 
Miller, R. (2014). Devolving the carceral state: Race, prisoner reentry, and the micro-politics of urban poverty management. Punishment \& Society, 16, 305-335.

Miller, J. (2015). Contemporary modes of probation officer supervision: The triumph of the “synthetic" officer? Justice Quarterly, 32(2), 314-336.

Miller, J., \& Maloney, C. (2013). Practitioner compliance with risk/needs assessment tools a theoretical and empirical assessment. Criminal Justice and Behavior, 40(7), 716-736.

National Institute of Corrections. (2003). Topics in Community Corrections. Washington, DC: U.S. Department of Justice.

Oleson, J. C., VanBenschoten, S., Robinson, C., Lowenkamp, C. T., \& Holsinger, A. M. (2012). Actuarial and clinical assessment of criminogenic needs: identifying supervision priorities among federal probation officers, Journal of Crime and Justice, 35(2), 239-248.

[Previous work by the authors] (2016). Washington, DC: SAGE Publications.

Robinson, G. (2015). Three narratives and a funeral: Community punishment in England and Wales. In G. Robinson \& F. McNeill (Eds)., Communitty punishment: European perspectives (pp. 30-50). New York: Routledge.

Robinson, G., \& McNeill, F. (2008). Exploring the dynamics of compliance with community penalties. Theoretical Criminology, 12, 431-449.

Shook, J. J., \& Sarri, R. C. (2007). Structured decision making in juvenile justice: Judges' and probation officers' perceptions and use. Children and Youth Services Review, 29(10), $1335-1351$.

Skeem, J., \& Manchak, S. (2008). Back to the future: From Klockar's model of effective supervision to evidence-based practice in probation. Journal of Offender Rehabilitation, 47(3), 220-247. 
Solomon, A., Osborne, J., Winterfield, L., Elderbroom, B., Burke, P., Stroker, R., Rhine, E., \& Burrell, W. (2008). Putting public safety first: 13 parole supervision strategies to enhance re-entry outcomes. Washington, DC: Urban Institute.

Taxman, F. S. (2008). No illusions: Offender and organizational change in Maryland's proactive community supervision model. Criminology and Public Policy, 7(2), 275-302.

Taxman, F.S. \& Pattavina, A. (Eds.) (2013). Simulation Strategies to Reduce Recidivism: Risk Need Responsivity (RNR) Modeling for the Criminal Justice System. New York: Springer.

Taxman, F. S., Yancey, C., \& Bilanin, J. E. (2006). Proactive community supervision in Maryland: Changing offender outcomes. Maryland Division of Parole and Probation.

Turner, S. (2010). Case management in corrections: Evidence, issues and challenges. In F. McNeill, P. Raynor, \& C. Trotter (Eds.), Offender supervision: New directions in theory, research and practice (pp. 344-366). New York: Willan.

Viglione, J., Rudes, D. S., \& Taxman, F. S. (2015). The myriad of challenges with correctional change: From goals to culture. European Journal of Probation, 7(2), 103-123.

Vincent, G.M., Guy, L.S., Gershenson, B.G. \& McCabe, P. (2012). Does risk assessment make a difference? Results of implementing the SAVRY in juvenile probation, Behavioral Sciences and the Law, 30(4), 384-405.

West, A.D. \& Seiter, R.P. (2004) Social worker or cop? Measuring the supervision styles of probation \& parole officers in Kentucky and Missouri, Journal of Crime and Justice, 27(2), 27-57. Yang, M., Wong, S. C. P., \& Coid, J. (2011). The efficacy of violence prediction: A meta-analytic comparison of nine risk assessment tools. Psychological Bulletin, 136(5), $740-767$.

Ziv, R. (2017). The future of correctional rehabilitation: Moving beyond the RNR model and Good Lives Model debate. London: Routledge. 


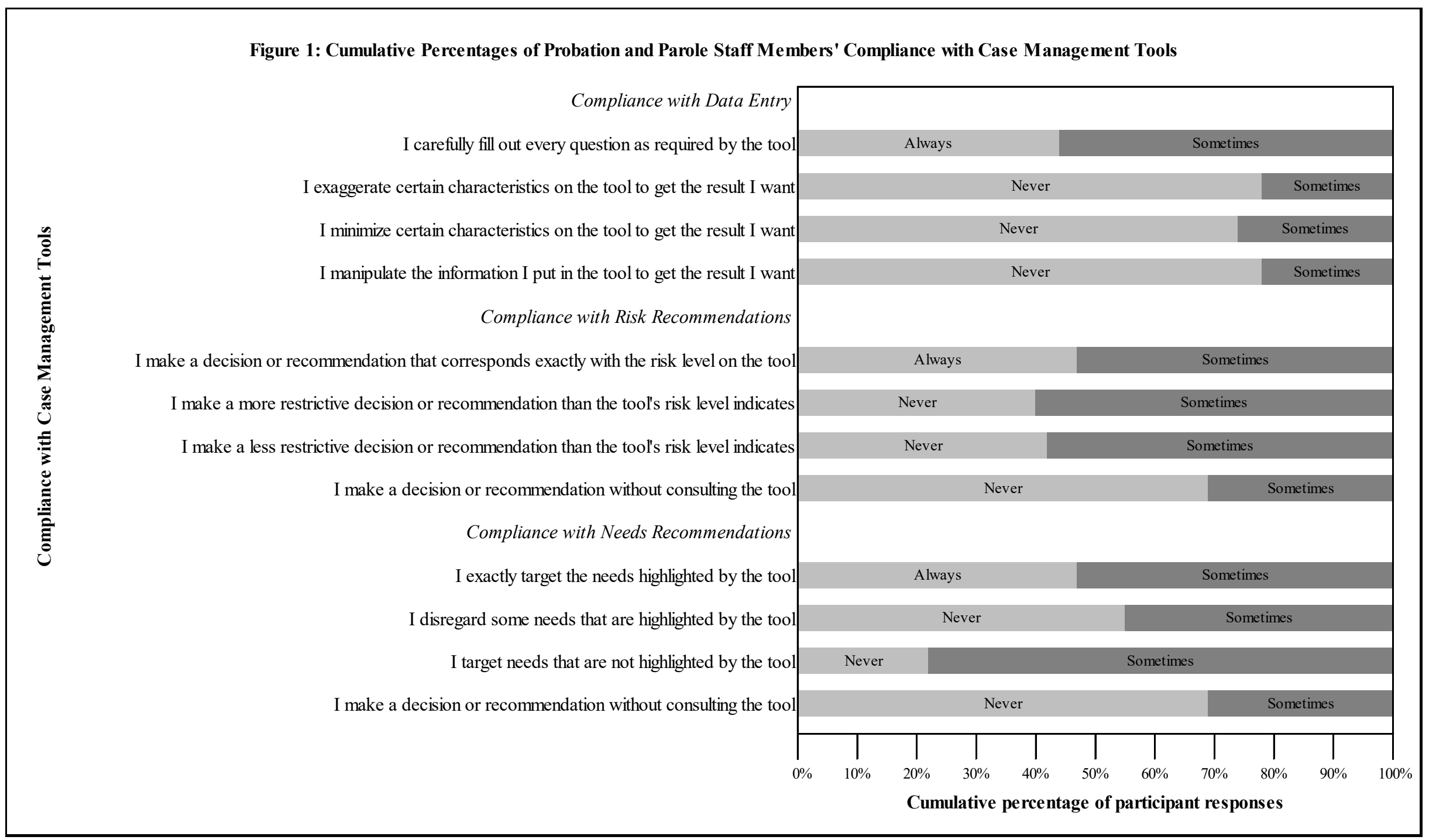


Table 1: Multivariate Logis tic Regression of Assessment Compliance with Data Entry

\begin{tabular}{|c|c|c|c|c|c|c|c|c|c|c|c|c|}
\hline \multirow[b]{2}{*}{ Professional Characteristics } & \multicolumn{3}{|c|}{$\begin{array}{c}\text { Model 1: } \\
\text { I carefully fill out every } \\
\text { question as required } \\
\text { by the tool } \\
(0=\text { Always; } 1=\text { Sometimes })\end{array}$} & \multicolumn{3}{|c|}{$\begin{array}{c}\text { Model 2: } \\
\text { I exaggerate certain } \\
\text { characteristics on the tool } \\
\text { to get the result I want } \\
(0=\text { Never; } 1=\text { Sometimes })\end{array}$} & \multicolumn{3}{|c|}{$\begin{array}{l}\text { Model 3: } \\
\text { I minimize certain } \\
\text { characteristics on the tool } \\
\text { to get the result I want } \\
(0=\text { Never; } 1=\text { Sometimes })\end{array}$} & \multicolumn{3}{|c|}{$\begin{array}{c}\text { Model 4: } \\
\text { I manipulate the } \\
\text { information I put in the tool } \\
\text { to get the result I want } \\
(0=\text { Never; } 1=\text { Sometimes })\end{array}$} \\
\hline & $\underline{O . R}$. & s.e. & sig. & $\underline{O . R}$. & s.e. & $\underline{\text { sig. }}$. & $\underline{O . R}$. & s.e. & $\underline{\text { sig. }}$. & $\underline{O . R}$. & $\underline{\text { s.e. }}$ & sig. \\
\hline \multicolumn{13}{|l|}{ Position $^{1}$} \\
\hline Case manager & 4.977 & $(.602)$ & $* *$ & 3.873 & $(.818)$ & $\dagger$ & 4.097 & $(.802)$ & $\dagger$ & .258 & $(.623)$ & * \\
\hline Senior case manager & 2.760 & $(.491)$ & * & 1.669 & $(.582)$ & & 3.355 & $(.584)$ & * & .509 & $(.465)$ & \\
\hline Length of employment & 1.001 & $(.004)$ & & 1.035 & $(.008)$ & $* * *$ & 1.038 & $(.007)$ & $* * *$ & 1.002 & $(.004)$ & \\
\hline Perceptions of assessment validity scale & .916 & $(.208)$ & & 1.360 & $(.285)$ & & 1.407 & $(.256)$ & & .741 & $(.178)$ & $\dagger$ \\
\hline \multicolumn{13}{|l|}{ Job Burnout and Stress } \\
\hline Depersonalization scale & 1.364 & $(.259)$ & & 2.031 & $(.353)$ & * & 3.249 & $(.358)$ & $* * *$ & .551 & $(.307)$ & $\dagger$ \\
\hline Emotional exhaustion scale & .988 & $(.205)$ & & 1.882 & $(.293)$ & * & 1.497 & $(.282)$ & & 3.653 & $(.278)$ & $* * *$ \\
\hline Personal accomplishment scale & 1.286 & $(.220)$ & & .419 & $(.009)$ & $* *$ & .480 & $(.309)$ & $*$ & 1.919 & $(.320)$ & * \\
\hline \multicolumn{13}{|l|}{ Supervision Strategies } \\
\hline Surveillance scale & .543 & $(.265)$ & * & .400 & $(.412)$ & * & .527 & $(.368)$ & $\dagger$ & .277 & $(.348)$ & $* * *$ \\
\hline Rehabilitation scale & .438 & $(.429)$ & $\dagger$ & .297 & $(.544)$ & * & .468 & $(.503)$ & & .597 & $(.509)$ & \\
\hline Opportunity scale & 1.261 & $(.190)$ & & 1.574 & $(.276)$ & $\dagger$ & 1.454 & $(.248)$ & & 1.118 & $(.230)$ & \\
\hline \multicolumn{13}{|l|}{ Model Information } \\
\hline Constant & 70.000 & $(1.848)$ & & 14.589 & $(2.044)$ & & .306 & $(2.168)$ & & 18.932 & $(2.160)$ & \\
\hline Model $\chi^{2}$ & 31.931 & & $* * *$ & 64.455 & & $* * *$ & 76.517 & & $* * *$ & 56.818 & & $* * *$ \\
\hline Log likelihood & 232.694 & & & 135.706 & & & 148.417 & & & 181.550 & & \\
\hline Cox \& Snell $R^{2}$ & .148 & & & .275 & & & .318 & & & .223 & & \\
\hline
\end{tabular}

${ }^{\dagger} p<.10 ; * p<.05 ; * * p<.01 ; * * * p<.001$

Reference category: ${ }^{1}$ Other position 
Table 2: Multivariate Logistic Regression of Assessment Compliance with Risk Recommendations

\begin{tabular}{|c|c|c|c|c|c|c|c|c|c|c|c|c|}
\hline \multirow[b]{2}{*}{ Professional Characteristics } & \multicolumn{3}{|c|}{$\begin{array}{l}\text { Model 5: } \\
\text { I make a decision or } \\
\text { recommendation that } \\
\text { corresponds exactly with } \\
\text { the risk level on the tool } \\
(0=\text { Always; } 1=\text { Sometimes })\end{array}$} & \multicolumn{3}{|c|}{$\begin{array}{c}\text { Model 6: } \\
\text { I make a more restrictive } \\
\text { decision or recommendation } \\
\text { than the tool's risk level } \\
\text { indicates } \\
(0=\text { Never; } 1=\text { Sometimes })\end{array}$} & \multicolumn{3}{|c|}{$\begin{array}{c}\text { Model 7: } \\
\text { I make a less restrictive } \\
\text { decision or recommendation } \\
\text { than the tool's risk level } \\
\text { indicates } \\
(0=\text { Never; } 1=\text { Sometimes })\end{array}$} & \multicolumn{3}{|c|}{$\begin{array}{l}\text { Model 8: } \\
\text { I make a decision or } \\
\text { recommendation without } \\
\text { consulting the tool } \\
(0=\text { Never; } 1=\text { Sometimes })\end{array}$} \\
\hline & $\underline{O . R .}$ & s.e. & sig. & $\underline{O . R}$. & s.e. & sig. & $\underline{O . R .}$ & s.e. & sig. & $\underline{O . R}$. & s.e. & sig. \\
\hline \multicolumn{13}{|l|}{ Position $^{1}$} \\
\hline Case manager & 1.712 & $(.655)$ & & .181 & $(.649)$ & $* *$ & 1.520 & $(.484)$ & & 1.585 & $(.659)$ & \\
\hline Senior case manager & .628 & $(.509)$ & & .294 & $(.508)$ & $*$ & 3.493 & $(.430)$ & $* *$ & .616 & $(.482)$ & \\
\hline Length of employment & .995 & $(.004)$ & & 1.005 & $(.004)$ & & 1.047 & $(.009)$ & $* * *$ & 1.012 & $(.004)$ & $* *$ \\
\hline Perceptions of assessment validity scale & .971 & $(.196)$ & & .779 & $(.201)$ & & 1.941 & $(.185)$ & $* *$ & .792 & $(.188)$ & \\
\hline \multicolumn{13}{|l|}{ Job Burnout and Stress } \\
\hline Depersonalization scale & 1.077 & $(.275)$ & & 4.035 & $(.334)$ & $* * *$ & 2.301 & $(.289)$ & $* * *$ & 1.545 & $(.280)$ & \\
\hline Emotional exhaustion scale & 2.678 & $(.278)$ & $* * *$ & .536 & $(.246)$ & $*$ & 3.172 & $(.283)$ & $* *$ & 1.067 & $(.249)$ & \\
\hline Personal accomplishment scale & 1.180 & $(.264)$ & & 1.513 & $(.223)$ & $\dagger$ & 2.206 & $(.299)$ & $* * *$ & 1.086 & $(.240)$ & \\
\hline \multicolumn{13}{|l|}{ Supervision Strategies } \\
\hline Surveillance scale & .492 & $(.290)$ & $*$ & 2.744 & $(.293)$ & $* * *$ & .282 & $(.346)$ & $* * *$ & .376 & $(.346)$ & $* *$ \\
\hline Rehabilitation scale & 2.758 & $(.474)$ & $*$ & .696 & $(.461)$ & & .481 & $(.470)$ & & .997 & $(.444)$ & \\
\hline Opportunity scale & 1.845 & $(.211)$ & $* *$ & 1.413 & $(.210)$ & $\dagger$ & 2.132 & $(.251)$ & $* * *$ & 1.648 & $(.214)$ & * \\
\hline \multicolumn{13}{|l|}{ Model Information } \\
\hline Constant & .002 & $(2.051)$ & $* *$ & .022 & (1.981) & $\dagger$ & .047 & (1.959) & $* * *$ & 1.873 & (1.837) & \\
\hline Model $\chi^{2}$ & 55.656 & & $* * *$ & 48.570 & & $* * *$ & 103.800 & & $* * *$ & 45.784 & & $* * *$ \\
\hline Log likelihood & 213.517 & & & 218.544 & & & 144.440 & & & 202.457 & & \\
\hline Cox \&Snell $R^{2}$ & .248 & & & .220 & & & .310 & & & .209 & & \\
\hline
\end{tabular}

${ }^{\dagger} p<.10 ; * p<.05 ; * * p<.01 ; * * * p<.001$

Reference category ${ }^{1}$ Other position 
Table 3: Multivariate Logistic Regression of Assessment Compliance with Needs Recommendations

\begin{tabular}{|c|c|c|c|c|c|c|c|c|c|c|c|c|}
\hline \multirow[b]{2}{*}{ Professional Characteristics } & \multicolumn{3}{|c|}{$\begin{array}{c}\text { Model 9: } \\
\text { I exactly target the needs } \\
\text { highlighted by the tool } \\
(0=\text { Always; } 1=\text { Sometimes })\end{array}$} & \multicolumn{3}{|c|}{$\begin{array}{l}\text { Model 10: } \\
\text { I disregrard some needs } \\
\text { that are highlighted by } \\
\text { the tool } \\
\text { (0=Never; } 1=\text { Sometimes })\end{array}$} & \multicolumn{3}{|c|}{$\begin{array}{c}\text { Model 11: } \\
\text { I target needs that are } \\
\text { not highlighted by the tool } \\
(0=\text { Never; } 1=\text { Sometimes })\end{array}$} & \multicolumn{3}{|c|}{$\begin{array}{l}\text { Model 12: } \\
\text { I make a decision or } \\
\text { recommendation without } \\
\text { consulting the tool } \\
(0=\text { Never; } 1=\text { Sometimes })\end{array}$} \\
\hline & $\underline{O . R}$. & $\underline{\text { s.e. }}$ & $\underline{\text { sig. }}$. & $\underline{O . R}$. & s.e. & $\underline{\operatorname{sig}}$. & $\underline{O . R}$. & s.e. & sig. & $\underline{O . R}$. & s.e. & sig. \\
\hline \multicolumn{13}{|l|}{ Position $^{1}$} \\
\hline Case manager & 2.347 & $(.762)$ & & 3.309 & $(.659)$ & $\dagger$ & .555 & $(.912)$ & & .715 & $(.641)$ & \\
\hline Senior case manager & 2.780 & $(.590)$ & * & 1.596 & $(.525)$ & & 1.113 & $(.788)$ & & .542 & $(.483)$ & \\
\hline Length of employment & 1.009 & $(.004)$ & * & 1.004 & $(.004)$ & & .995 & $(.005)$ & & 1.013 & $(.004)$ & $* * *$ \\
\hline Perceptions of assessment validity scale & .565 & $(.234)$ & $*$ & .683 & $(.210)$ & $\dagger$ & .672 & $(.234)$ & $\dagger$ & .785 & $(.198)$ & \\
\hline \multicolumn{13}{|l|}{ Job Burnout and Stress } \\
\hline Depersonalization scale & 2.038 & $(.353)$ & * & 2.347 & $(.316)$ & $* *$ & .567 & $(.321)$ & $\dagger$ & .992 & $(.278)$ & \\
\hline Emotional exhaustion scale & 1.137 & $(.332)$ & & 1.127 & $(.244)$ & & 1.348 & $(.286)$ & & 1.222 & $(.243)$ & \\
\hline Personal accomplishment scale & .539 & $(.260)$ & * & 1.138 & $(.222)$ & & .659 & $(.304)$ & & 1.947 & $(.256)$ & $* *$ \\
\hline \multicolumn{13}{|l|}{ Supervision Strategies } \\
\hline Surveillance scale & 1.195 & $(.294)$ & & 1.179 & $(.280)$ & & .237 & $(.498)$ & $* *$ & .557 & $(.304)$ & $\dagger$ \\
\hline Rehabilitation scale & .797 & $(.508)$ & & .255 & $(.448)$ & $* *$ & 1.773 & $(.581)$ & & .305 & $(.490)$ & $*$ \\
\hline Opportunity scale & 5.411 & $(.275)$ & $* * *$ & 3.441 & $(.227)$ & $* * *$ & 2.135 & $(.262)$ & $* *$ & 1.911 & $(.220)$ & $* *$ \\
\hline \multicolumn{13}{|l|}{ Model Information } \\
\hline Constant & .133 & $(2.173)$ & & 1.943 & (1.903) & & 6.617 & $(2.401)$ & $* *$ & 2.376 & $(1.882)$ & \\
\hline Model $\chi^{2}$ & 87.323 & & $* * *$ & 52.419 & & $* * *$ & 26.200 & & $* *$ & 51.525 & & $* * *$ \\
\hline Log likelihood & 182.876 & & & 216.753 & & & 157.340 & & & 203.077 & & \\
\hline Cox $\&$ Snell $R^{2}$ & .361 & & & .236 & & & .126 & & & .232 & & \\
\hline
\end{tabular}

${ }^{\dagger} p<.10 ; * p<.05 ; * * p<.01 ; * * * p<.001$

Reference category ${ }^{1}$ Other position 